\title{
LA MEDIACIÓN COMO HERRAMIENTA EFICAZ EN LA PREVENCIÓN DE CONFLICTOS JURÍDICO PENALES DERIVADOS DE LA VIOLENCIA DE GÉNERO*
}

\author{
Yaíma Águila Gutiérrez** \\ Marileydis Pino Rosa***
}

\begin{abstract}
Resumen: La violencia de género es un fenómeno sociohistórico y cultural actual, que afecta a millones de personas en todo el mundo y cuyas repercusiones nocivas van desde el ámbito personal y familiar hasta el social, con consecuencias de deterioro de las relaciones interpersonales que pueden llegar a tipificar delitos múltiples. La mediación se presenta como una herramienta idónea a utilizar en un momento anterior a la intervención judicial, para re-
\end{abstract}

* Artículo presentado en la Vi Conferencia Internacional Mujer, Género y Derecho celebrada del 11 al 13 de mayo del 2011 en La Habana, Cuba.

** Licenciada en Derecho. Máster en Criminología. Aspirante a Doctora en Ciencias Pedagógicas. Profesora Auxiliar de la Universidad de Matanzas. Revisora de la Revista Médica Electrónica, de alto impacto. Miembro de la Unión de Juristas de Cuba y de la Sociedad de Pedagogos de Cuba. Matanzas, Cuba. Correo-e: yaima.aguila@umcc.cu

*** Licenciada en Derecho. Profesora Asistente de la Universidad de Matanzas. Miembro de la Unión de Juristas de Cuba. Correo-e: marileydis.pino@umcc.cu. Fecha de recepción: 19 de octubre de 2016. Fecha de modificación: 15 de noviembre de 2016. Fecha de aceptación: 24 de febrero de 2017. Para citar el artículo: YAÍMA ÁGUILA GUTIÉRREZ, MARILEYDis PinO RoSA. "La mediación como herramienta eficaz en la prevención de conflictos jurídico penales derivados de la violencia de género", en Revista Derecho Penal y Criminología, Vol. 37, n. 103 , julio-diciembre de 2016, Bogotá: Universidad Externado de Colombia, pp. 171-187, DOI: https://doi.org/10.18601/01210483.v37n103.08 
solver conflictos derivados de la violencia de género que se manifiesten en el ámbito social, laboral, familiar y cuyas consecuencias pueden trascender al ámbito del Derecho Penal, por tanto, son objeto de estudio de la criminología en su afán de prevenirlos.

Palabras clave: Violencia de género, prevención, mediación.

\title{
THE MEDIATION AS AN APT TOOL FOR THE PREVENTION OF CRIME AS RESULT OF GENDER VIOLENCE
}

\begin{abstract}
Violence based in gender is an actual, social, historical and cultural matter. It affects to million persons around the world in the personal, familiar and social ambit. Violence based in gender could damage relationships and also could become in a crime. Mediation is an apt tool to use before the intervention of law for solving gender violence's conflicts which could need the intervention of criminal law. Those reasons show that is necessary the prevention of gender violence so is important the intervention of criminology. Key words: violence, gender, prevention, mediation.
\end{abstract}

\section{INTRODUCCIÓN}

Actualmente la mediación se ha convertido en la solución más deseada y practicada en el mundo para resolver conflictos. Cuba ha servido de mediador entre las FARC y el Gobierno colombiano; el Gobierno canadiense sirvió de mediador en el restablecimiento de las conversaciones entre Cuba y Estados Unidos. La mediación se ha convertido en la herramienta idónea para resolver, además, conflictos que se dan en el ámbito social, laboral, familiar y cuyas consecuencias pueden trascender al ámbito del Derecho Penal, por tanto, son objeto de estudio de la criminología en su afán de prevenirlos.

Muchos de los conflictos que se suscitan en la sociedad están motivados por las brechas de género y la violencia de género. La violencia de género es un fenómeno sociohistórico y cultural actual, que afecta a millones de personas en todo el mundo y puede darse en cualquier escenario del desarrollo de los seres humanos. Constituye un grave problema para la humanidad que afecta, sobre todo, a mujeres y niñas, aunque nadie está exento de sufrirla.

Las repercusiones nocivas de este tipo de violencia van desde el ámbito personal y familiar hasta el social, con consecuencias de deterioro no solo de la salud, también de las relaciones interpersonales y pueden llegar a tipificar delitos múltiples (Hernández, 2014). Puede producirse en cualquiera de los ámbitos de la vida cotidiana y aunque suele ser más frecuente en las relaciones familiares y de pareja, también puede manifestarse en otros espacios sociales como el ámbito laboral y las instituciones escolares, entre otros (Valdés et al., 2012). 
La expresión de la violencia por razones de género puede ser física, sexual, económica, psicológica, a modo de libertades restringidas, coerción y amenazas (Calvo y Camacho, 2014). Todas estas manifestaciones pueden darse en el ámbito privado como en el público y tanto mujeres como hombres, ancianos, niños y adolescentes pueden ser víctimas y/o victimarios.

Al ser una construcción social y cultural de un espacio determinado, varía de acuerdo a la zona geográfica y a la época en que se estudia.

Estas razones demuestran que es un tema multifactorial que requiere un tratamiento multisectorial, en el que se realice un trabajo conjunto entre sociólogos, pedagogos, psicólogos, psiquiatras y juristas.

Existen manifestaciones de violencia de género, que se han asumido durante siglos como roles de género impuestos por la sociedad y que resulta difícil identificarlas. En estos casos es imprescindible la función mediadora.

Al determinarse a los seres humanos como bio-psico-sociales, es necesario un estudio interdisciplinario que permita entender su comportamiento, conocer las bases para la mediación, sus efectos en el ámbito jurídico y el empleo de la mediación como solución a estos conflictos en un momento anterior a la intervención de la ley.

La gente responde al conflicto en una variedad de formas. Una persona se refugiará en el silencio, otra responderá mediante una confrontación abierta, una tercera comenzará a negociar. La misma persona puede responder de diversas maneras a distintos tipos de conflictos. Esas reacciones no solo resultan de la naturaleza misma de conflictos específicos, sino también de la historia personal, que determina decisivamente las actitudes y creencias de cada persona de cara al conflicto (Krabill, 2003).

La mediación con frecuencia significa convertirse en un puente entre personas que son incapaces de, o carecen de la disposición para hablar entre sí (Doucet, 1998). Las reacciones emocionales pueden nublar la habilidad para comprender una situación de conflicto con un mínimo grado de objetividad. En consecuencia el mediador será desafiado constantemente a aportar un análisis claro y objetivo de una situación conflictiva; generada, en el caso que nos ocupa por el ejercicio de la violencia de género (Flanders, 1994).

Los objetivos fundamentales del presente trabajo consisten en demostrar la relación existente entre la violencia de género y la ocurrencia de delitos y mostrar la mediación como una alternativa a la prevención situacional del delito o prevención primaria del mismo, al generarse como consecuencia del ejercicio de violencia de género. 


\section{LA VIOLENCIA DE GÉNERO COMO FENÓMENO DEL CUAL PUEDEN DERIVAR CONSECUENCIAS JURÍDICO-PENALES}

La violencia de género se presenta como un fenómeno actual que motiva la reflexión y el estudio desde diversas ramas del conocimiento y que ha captado la atención internacional.

La Organización Mundial de la Salud (OMS) alertó en el año 2012 que la violencia contra las mujeres y niñas constituye un problema de proporciones pandémicas. Se identifica así este tipo de violencia como un problema de salud alarmante, destacando la propia organización que los actos de violencia contribuyen al 15\% de la carga mundial de enfermedad (López-Cepero Borrego et al., 2010).

La Organización Panamericana de la Salud (OPS), al pronunciarse sobre la violencia de género como un problema de salud que aqueja mayormente al sexo femenino declaró (Artiles, 2012) que a finales de la década de los noventa la violencia de género causó más muertes e incapacidad entre las mujeres de quince a cuarenta y cuatro años que el cáncer, la malaria, los accidentes de tráfico e incluso que la guerra.

En informes rendidos por el Fondo de las Naciones Unidas para la Infancia (Unicef), desde hace varios años, se presenta la violencia de género como un problema que afecta a niñas y niños (Artiles, 2012).

En los últimos dos años del siglo xx en América Latina, solo uno de cada tres casos de abuso sexual era denunciado, y el $80 \%$ de dichas denuncias correspondían a niñas o adolescentes. El 30\% y 50\% de las víctimas de violación o intento de violación tenían menos de 15 años y alrededor del $20 \%$ tenían menos de 10 años, según estudios realizados en Chile, Perú, Malasia y Estados Unidos. En estos porcentajes se incluyen tanto niñas como niños, aunque las primeras son las principales víctimas (Artiles, 2012).

El tema de violencia de género se relaciona indisolublemente con cuestiones de sexualidad que imponen el dominio de términos como género, sexo, igualdad y equidad de género, roles de género, violencia de género, entre otros cuyo conocimiento impreciso de su significado pudiera provocar una comprensión incompleta o errada del presente trabajo. En aras de evitar un resultado de tal naturaleza, se dedican algunas líneas a la explicación de los mencionados términos.

El sexo se considera como el conjunto de características físicas, biológicas, anatómicas y fisiológicas que distinguen a los seres humanos, que permiten diferenciar a hombres y mujeres desde el nacimiento. El sexo hace referencia a las diferencias biológicas entre hombres y mujeres (Castro, 2006). 
Fue la francesa Simone de Beauvoir (2000) quien orientó las bases para configurar la categoría de género al afirmar en 1949 que "una mujer no nace, sino que se hace" (Valdés et al., 2012).

La autora asume que: "El género es una construcción sociocultural e histórica sobre el conjunto de características, funciones, significados, identidades, relaciones y comportamientos atribuida a las personas de acuerdo a su sexo, es una concepción de lo masculino y lo femenino que ha fraguado una cultura" (Valdés et al., 2012, p.17).

La categoría género, como construcción sociohistórica y cultural, no es una estructura estable, es un proceso y como tal está sujeto a cambios. Es posible a lo largo de la vida cambiar la cosmovisión de género de un sujeto, en tanto la persona puede cambiar así, como la sociedad, los valores, normas y manera de juzgar los hechos.

A través de la socialización de género los sujetos se apropian de cosmovisiones, conductas y relaciones que se corresponden con los modelos de lo femenino y lo masculino. La identidad de género y el rol de género son componentes de la socialización de género de obligatoria referencia, ya que de su apreciación depende que se califiquen como violentos algunos actos en materia de género que históricamente se han identificado como normales por la concepción cultural que sobre ellos existe, demostrando supremacía de poder o inequidad de derechos y obligaciones.

La identidad de género es definida como la conciencia y sentimiento íntimos de ser hombre, mujer, masculino, femenino o ambivalente (González y Castellanos, 2003). El rol de género se refiere a las normas de conducta que una sociedad concreta asigna a determinadas personas y cómo ellas asumen y expresan esas asignaciones en su vida cotidiana. Los estereotipos de género constituyen simplificaciones e ideas preestablecidas, socialmente generados, que se generalizan y atribuyen a las personas por el hecho de pertenecer a uno u otro sexo.

Mucho se habla de la igualdad de género como la base necesaria para la eliminación de formas discriminatorias y la prevención de la violencia de género, pero realmente no puede atribuírsele igualdad a la categoría de género, porque desde las características biológicas que diferencian las funciones o relaciones atribuidas o establecidas, respectivamente, se establecen diferencias. Existen funciones que, con independencia de la identidad de género de las personas, son ejercidas solo por mujeres por sus características biológicas, como la lactancia materna. Sin embargo, determinadas relaciones, de manera usual, no pueden establecerse por mujeres porque anatómicamente no poseen las características necesarias para asumirlas, por ejemplo, las relaciones laborales que exijan el uso de fuerza física que la mujer, por lo general, no posee (estibadora de un puerto).

Es la equidad de género la categoría que pudiera lograr la eliminación de la discriminación y la prevención de la violencia de género. La igualdad implica paridad, 
la equidad reconoce las diferencias existentes entre las personas y sus distintas posiciones en nuestra sociedad, teniendo esto en cuenta para determinar estrategias para alcanzar una igualdad de oportunidades. La verdadera equidad entre mujeres y hombres significa alcanzar la igualdad manteniendo el reconocimiento a la diferencia (Valdés et al., 2012).

Se han ofrecido varios conceptos de violencia de género a lo largo de la historia, la autora ha asumido que violencia de género: "concierne a todos los actos u omisiones mediante los cuales se daña, discrimina, ignora, somete y subordina a otra persona en los diferentes aspectos de su existencia por razones relacionadas con el género, por transgredir los modelos hegemónicos de lo masculino y lo femenino" (Valdés et al., 2012,p.29). Habrá siempre que se ejerza violencia desde una persona sobre otra, en relación con las concepciones de género que se defiendan o se intenten preservar.

Se manifiesta de diversas formas (Calvo y Camacho, 2014), entre las cuales destacan la violencia física, psicológica (forma más sutil de violencia), sexual, económica, entre otras (Valdés et al., 2012).

Se define como violencia física: aquella que puede ser percibida objetivamente por otros, que más habitualmente deja huellas externas. Está dirigida a ocasionar un daño o sufrimiento sobre la persona agredida como son hematomas, contusiones, excoriaciones, dislocaciones, quemaduras, pellizcos, pérdida de dientes, empujones o cualquier otro maltrato que afecte la integridad física de las personas, así como toda conducta destinada a producir daño a los bienes que integran el patrimonio de la víctima.

La autora reconoce la violencia psicológica como aquella que:

\begin{abstract}
Aparece inevitablemente siempre que hay otro tipo de violencia. Supone amenazas, insultos, humillaciones, desprecio hacia la propia persona, desvalorizando su trabajo, sus opiniones. Implica una manipulación en la que incluso la indiferencia o el silencio provocan en ella sentimientos de culpa e indefensión, incrementando el control y la dominación del agresor sobre la víctima. La víctima no se da cuenta hasta que el abuso, la manipulación y el maltrato se han instaurado crónicamente en la relación. Por lo general la toma de conciencia y la búsqueda de ayuda llegan cuando la autoestima ya se encuentra disminuida y gravemente lesionada.
\end{abstract}

Dentro de esta última categoría podrían incluirse otros tipos de violencia que llevan aparejado sufrimiento psicológico para la víctima y utilizan las coacciones, amenazas y manipulaciones para lograr sus fines, incurriendo en la comisión de múltiples delitos.

Se trataría de la violencia "económica", en la que el agresor hace lo posible por controlar el acceso de la víctima al dinero, tanto por impedirle trabajar de forma 
remunerada, como por obligarle a entregarle sus ingresos, haciendo él uso exclusivo de los mismos (llegando en muchos casos a dejar el agresor su empleo y gastar el sueldo de la víctima de forma irresponsable, obligando a esta a solicitar ayuda económica a familiares o servicios sociales).

También es habitual la violencia "social", en la que el agresor limita los contactos sociales y familiares de la víctima, aislándola de su entorno y limitando así un apoyo social importantísimo en estos casos.

Otro tipo de violencia que reconoce la autora es la Violencia sexual, como:

Toda conducta que vulnera el derecho de la persona a decidir libremente sobre su sexualidad, comprende el acceso carnal violento y toda forma de contacto sexual no genital impuesto, donde no media la voluntad del otro, el no permitir la utilización de métodos anticonceptivos, presiones para abortar y menosprecio sexual. Se ejerce mediante presiones físicas o psíquicas que pretenden imponer una relación sexual no deseada mediante coacción, intimidación o indefensión.

Aunque podría incluirse dentro del término de violencia física, se distingue de aquella en que el objeto es la libertad sexual, no tanto su integridad física. Es la más visible, y por tanto facilita la toma de conciencia de la víctima, pero también ha supuesto que sea la más comúnmente reconocida social y jurídicamente, en relación fundamentalmente con la violencia psicológica (Pick et al., 2010).

Por último, una de las más sutiles formas de violencia identificada es la violencia verbal. "Consiste en que el agresor asume comportamiento como menospreciar, insultar, humillar, ridiculizar, manipular e inducir a la confusión”.

Existen varios tipos de violencia de género y no de todos pueden derivarse la comisión de delitos, por lo cual no todos dan lugar al nacimiento de una relación jurídico-penal de manera directa porque a través suyo no pueden dañarse o ponerse en peligro bienes jurídicos protegidos penalmente. Para ejemplificar lo antes dicho puede plantearse que no toda violencia de género verbal genera un hecho delictivo, sino aquella que lacere o ponga en peligro un bien jurídico protegido (delito de Desacato, delito contra el Derecho de Igualdad -si contiene la conducta el elemento subjetivo exigido en la figura delictiva-, Difamación, Calumnia e Injuria). Igual análisis merece la violencia psicológica (Amenazas y Coacción).

Sin embargo, con frecuencia sucede que una manifestación de una forma de violencia que no genera la comisión de un delito se concatena con otra de la cual deriva una modalidad delictiva. La autora ha llamado a este fenómeno violencia de género en cadena y es cuando a partir de un conflicto se genera determinada violencia de género que no es de interés para el Derecho Penal al no poner en peligro ni dañar 
bienes jurídicos penalmente protegidos pero que desencadena otro tipo de violencia de género a partir del cual se pone en peligro o se daña un bien jurídico penalmente protegido y se tipifica un delito.

Algunos delitos contra la vida y la integridad personal, de modo frecuente, surgen como consecuencia del ejercicio de violencia física que a su vez es el resultado de una discusión en la que hubo violencia verbal e incluso psicológica, dos ejemplos clásicos son la Riña Tumultuaria y el Homicidio o asesinato, sobre todo cuando es un crimen pasional.

\section{LA PREVENCIÓN DE CONFLICTOS JURÍDICO-PENALES}

La necesidad de prevenir este fenómeno queda demostrada en el acápite anterior, pero además se fundamenta porque cada vez son más jóvenes las personas cuando comienzan a ejercer violencia de género, por tanto, la criminalidad aumenta en edades en las que los sujetos activos de los delitos derivados de actos violentos son inimputables. De esta manera se genera un mayor índice de impunidad delictiva.

En los últimos años la preocupación respecto de este tipo de violencia se ha desplazado a los jóvenes, dado que la conducta agresiva durante la niñez y la adolescencia ha sido identificada como un fuerte predictor de violencia posterior, el inicio precoz de las tendencias agresivas se asocia con violencia severa y crónica, no solo durante la adolescencia sino también durante la adultez (Póo y Vizcarra, 2008, p.1).

La prevención de conductas delictivas derivadas del ejercicio de la violencia de género es un tema que atañe a todas las disciplinas del Derecho por la naturaleza misma del fenómeno y por los ámbitos en que puede manifestarse. Distinto a como pudiera percibirse, no es un tema que queda en el éter, sino que concierne y debería interesar a todos los estudiosos del Derecho. Resulta un fenómeno multicausal, complejo y que requiere una mirada holística para su solución.

La ficticia división de saberes que el hombre ha hecho en el afán de lograr un orden metodológico en sus estudios y mayor profundización en el conocimiento de determinados fenómenos no debe limitar la capacidad de integración ni de observación de los cientistas, mucho menos de aquellos que tratan temas que tienen como objeto de estudio al hombre. Las ciencias jurídicas tienen como encomienda primordial lograr el orden y el adecuado funcionamiento de una sociedad a partir de la regulación de los deberes y derechos, de las conductas o relaciones sociales, de los sujetos que la integran; de ahí que cualquier solución a conflictos de tal naturaleza deba ser interdisciplinaria. 
Existen diversas definiciones de prevención que contemplan la complejidad de las relaciones sociales. La prevención, según Carvajal (2006), se dirige en su nivel primario a la toma de medidas para evitar que se produzcan insuficiencias, se realiza en un marco supuestamente sano sobre individuos incorporados a grupos de riesgos de carácter biológico, psicosocial, económico y ambiental, que asociados pueden producir una alteración determinada, y comprometer el desarrollo normal de los niños, adolescentes, jóvenes y adultos.

Pueden distinguirse varios niveles de prevención (Fernández, 2008).

Como parte de la prevención primaria (Almeida, 2005), que se anticipa a la aparición de las causas que puedan favorecer el surgimiento de trastornos en el desarrollo del individuo y se encaminan en un medio sano; incidiendo en los mecanismos de aprendizaje, desarrollo y formación en la socialización. En esta pueden identificarse, a su vez, dos niveles:

- Prevención primaria inespecífica: persigue ejercer influencia sobre todos los elementos y factores determinantes del problema.

- Prevención primaria específica: se relaciona más con un problema determinado e incide directamente sobre los factores que se supone lo generan; pueden ser la historia personal, el entorno familiar, el tipo de vida y las relaciones sociales. El conocimiento y la profundización de estos factores de riesgo aportan material de estudio sobre el cual se pueden armar estrategias preventivas.

Un segundo nivel es el de prevención secundaria, que intenta solucionar un problema ya existente, intenta hacerlo desaparecer por completo o en parte. Se dirige a la reducción de las situaciones de desventajas o problemáticas así como a la intensidad de estas.

El siguiente nivel es el de prevención terciaria o prevención terapéutica: su fundamental objetivo es disminuir las consecuencias negativas del fenómeno (Villavicencio, 2006).

Recientemente una nueva nomenclatura ha cobrado fuerza. A partir de ella se diferencia la prevención en: universal, selectiva e indicada. La prevención universal se dirige a los miembros de un grupo, beneficiándolos a todos por igual. La prevención selectiva es aquella que se dirige a un subgrupo que tiene un riesgo mayor que el promedio para tener una conducta que se desea evitar. Se dirige a grupos de riesgo. Por último, la prevención indicada es más intensiva y más costosa. Se dirige a un subgrupo concreto de la comunidad que suele ya tener un problema.

La prevención consiste en un proceso a partir del cual se crean condiciones y/o atributos personales que promueven el bienestar de las personas. La autora asume la 
definición criminológica de prevención de Coy y Martínez (2006), siendo establecida a partir de sus clasificaciones en primaria, secundaria y terciaria:

La prevención primaria se dirige a poner en práctica todo un conjunto de medidas que puedan conseguir, al menos, hacer disminuir si no desaparecer, el propio fenómeno de la desviación en general o de la delincuencia en particular, mientras las condiciones político-económicas no permitan soluciones de más amplio alcance (Coy y Martínez, 2006, p.124).

La prevención Secundaria "busca la identificación temprana de aquellas personas que se presuma que pueden llegar en su día a convertirse en desviados o delincuentes" (Coy y Martínez, 2006, p. 125).

La prevención Terciaria "tiene por objeto la reducción, rehabilitación, resocialización, reinserción social, según los usos terminológicos de los distintos estudios, de aquellos sujetos que ya han llegado a realizar comportamientos desviados o delincuentes" (Coy y Martínez, 2006, p. 125).

Las Ciencias Penales y Criminológicas persiguen diversos fines, dentro de ellos los de reprimir y prevenir y muchas veces lo percibimos en este orden, o sea, primero reprimir y luego prevenir, cuando debería ser al revés. La prevención primaria de los delitos pudiera ser la solución al congestionamiento judicial en las salas penales de los tribunales.

\section{LA MEDIACIÓN EN LA PREVENCIÓN PRIMARIA O SITUACIONAL DEL DELITO ES UNA HERRAMIENTA PREJUDICIAL PARA LA SOLUCIÓN DE CONFLICTOS DERIVADOS DE LA VIOLENCIA DE GÉNERO}

La mediación se presenta como una solución pre y extrajudicial a conflictos derivados del ejercicio de la violencia de género que pudieran en el futuro tener repercusiones jurídico-penales por existir determinada proclividad a poner en peligro o lacerar bienes jurídicos penalmente protegidos a partir de conductas que se desencadenan.

La mediación se presenta entonces como un recurso que permite solucionar el conflicto antes de que se tipifique el delito, lo cual también contribuiría a descongestionar las salas penales de los tribunales, en tanto disminuiría la radicación de delitos o el índice delictivo.

Es posible que la habilidad que se tenga para enfrentar los conflictos determine el lugar de la sociedad en el futuro. Las cifras de delitos pueden aumentar la desesperación, el desamparo y el desconsuelo de una sociedad que se siente abatida y fatigada con una lucha por el respeto a la vida y los derechos humanos. 
Hay un mecanismo que aparece bajo las teorías de la justicia restaurativa y la resolución de conflictos, denominado mediación, que podría ser útil frente a la situación que vive la sociedad y frente a las necesidades que se le plantean de cara a su conflicto.

Dice Suárez: "La mediación es un dispositivo no adversarial de resolución de disputas, que incluye un tercero neutral cuya función es ayudar a que las personas que están empantanadas en la disputa puedan negociar en forma colaborativa y alcanzar una resolución de la misma” (Suárez, 2003, pp. 28 y 29).

Al decir que la mediación es un dispositivo "no adversarial", la definición plantea que los participantes del conflicto están llamados a identificar los intereses que se tienen en común. Es frecuente encontrar que se tienen posiciones frente a los problemas, pero estas posiciones no son en realidad más que el ropaje de los intereses compartidos en común. Cuando se parte de los propios deseos, o en este caso de los propios intereses, es muy difícil comprender al otro.

Por otro lado, es interesante señalar que una forma de comenzar la discusión acerca de la mediación es buscando los orígenes semánticos de la palabra. En ese sentido, la etimología de la palabra mediación dice que viene del latín Mediatio, -onis, que significa: 1) F. Acción y efecto de mediar. Y por mediar se entiende: 2) Intr. Interceder o rogar por alguien. 3) Intr. Interponerse entre dos o más que riñen o contienden, procurando reconciliarlos y unirlos en amistad. De este modo, la mediación puede ser entendida como la herramienta que pone a un tercero neutral en medio de dos o más partes en conflicto.

Las ventajas de la mediación en materia penal -justicia restaurativa- es que el acuerdo autocompuesto conforme a la ley, incluyendo la reparación y el perdón, dan resultados más eficientes que la tradicional respuesta punitiva que hasta la actualidad solo demostró el fracaso de las instituciones carcelarias como espacio de rehabilitación social (...) en definitiva, la mediación es un proceso de justicia restaurativa, que tiene en cuenta la prevención del delito desde la mediación (Del VaL, 2006, p. 67).

En el contexto actual, es claro que la mediación deberá cumplir con los propósitos de una sociedad que busca solucionar sus conflictos y apaciguar el dolor y la angustia de sus víctimas, y deberá hacerse desde el marco de actuación de la justicia restaurativa. De ahí lo que señalan Segovia y Ríos:

A nuestro juicio, sigue siendo verdad que "una buena teoría es condición de posibilidad de una buena praxis". Por eso, el horizonte desde el que hay que contemplar la mediación -especialmente ante su eventual traducción al derecho procesal-es el de la justicia restaurativa. Esta supone una concepción fuerte, abierta y positiva del ser humano, de la sociedad y "otra" idea de Justicia de contornos todavía no perfectamente definidos, pero claramente perfilables por 
oposición a la justicia retributiva y que van siendo traducidos en documentos y prácticas de los organismos especializados de la Organización de Naciones Unidas (Segovia y Ríos, 2008, p. 79).

La justicia restaurativa no es solo una apuesta para el contexto de violencia que tenemos, ha mostrado sus fortalezas y sus debilidades en otros escenarios. Lo importante es tener claro cuáles son sus alcances y los propósitos de la implementación de los mismos. No es inútil advertir que las sociedades problematizadas por conflictos han encontrado en la justicia restaurativa un modelo interesante para pacificarse, y uno de los mecanismos que ha sido compatible con los principios de dicha justicia restaurativa ha sido el de la mediación.

La mediación no es un recurso nuevo para la resolución de los conflictos. Ha existido siempre. La historia está llena de ejemplos en los que algunas personas de la comunidad, como los líderes religiosos o personas con autoridad o influencias, actuaban como instancia directa cuando se acudía a ellos en busca de la resolución de los conflictos, cuando estos se presentaban. En la medida en que el Estado organiza y toma para sí la función de impartir justicia, la mediación va perdiendo el papel relevante que poseía (Romero, 2002, p. 32).

Caireta Sampere la propone de la siguiente forma:

Entendemos la mediación como aquella técnica en que dos partes o más, involucradas en un conflicto, después de ensayar diferentes posibilidades concluyen que no pueden resolverlo solas y deciden pedir una tercera que les ayude en su proceso. Para que la mediación sea exitosa deben ocurrir dos cosas: que las necesidades contrapuestas se vean resueltas en lo más esencial y que la relación entre las partes salga reforzada (Caireta Sampere, 2008, p. 15).

Una de las partes más complejas en el tema de la mediación tiene que ver, posiblemente, con el papel del mediador y la neutralidad de este frente al conflicto y las partes. De ahí que su función sea de compañía. Su presencia acompaña la búsqueda de respuestas, como lo indica Gozaini, sin que se convierta en juez:

A través de la mediación se persigue incorporar la denominada justicia coexistencial, donde el órgano actuante "acompañe" a las partes en conflicto, orientándolas con su consejo en la búsqueda racional de respuestas superadoras de crisis. La mediación incorpora otro elemento objetivo para la solución del conflicto. Se trata de ejercer una tarea de saneamiento independiente en los intereses de cada parte (Gozaini, 2009, p. 97).

En cuanto a los intereses que tienen las partes, el papel de la mediación, y específicamente el mediador, es ayudar a que estas logren dar el salto de los intereses particulares a la identificación de las necesidades que las unen. Al respecto, Ripól dice: 
La mediación pude ser definida como una intervención en un conflicto o en una negociación por parte de una tercera persona aceptable a las partes, imparcial y neutra, sin ningún poder de decisión y que pretende ayudarlas a que ellas mismas desarrollen un acuerdo (una entente) viable, satisfactorio y capaz de responder a las necesidades de todos los miembros (Ripól, 2001, p. 44).

La mediación, desde sus posibilidades, puede referirse a la reparación del daño, a la restitución o resarcimiento de los perjuicios causados, a la realización o abstención de determinada conducta, y a la prestación de servicios a la comunidad. Es importante señalar en este punto lo que dice Wilde: "La mediación nada tiene que ver con soluciones impuestas por una tercera persona ajena a las partes, sino que es una decisión emanada de ellas mismas, a la cual han arribado alentadas y ayudadas por un mediador" (Wilde, 2000, p. 9).

Obarrio, por su parte, habla de la mediación en estos términos: "Defino la mediación como un proceso en el que las partes en conflicto deciden intentar la búsqueda de una solución a sus intereses en pugna de una manera cooperativa, con la ayuda de un tercero llamado mediador" (Obarrio, 2009, p. 36).

Queda claro, entonces, que la mediación es un concepto con diversas posibilidades interpretativas y que tiende a varios propósitos y posibilidades que deben ser analizados con detenimiento de tal modo que pueda entenderse la dimensión real del concepto.

No obstante todas las definiciones presentan a la mediación como una vía de solución de conflictos que favorece la prevención de conductas delictivas.

\section{CONCLUSIONES}

1. La violencia de género es un problema actual de proporciones pandémicas que afecta cada vez a personas más jóvenes convirtiéndolos en sujetos activos y pasivos de delitos múltiples.

2. La prevención primaria de los delitos surgidos del ejercicio de la violencia de género se presenta como la solución más favorable para disminuir la criminalidad y favorecer así el descongestionamiento de las salas penales de los tribunales.

3. La mediación es una herramienta idónea para solucionar de modo prejudicial y extrajudicial los conflictos generados por violencia de género que pudieran en el futuro generar una relación jurídico penal. 


\section{BIBLIOGRAFÍA}

ARtiles de León, IleAna (2012). Salud y violencia de Género. La Habana, Cuba: Facultad de Ciencias Médicas Comandante Manuel Fajardo.

AugsBuRger, DAVID (1984). ¿Diferencias personales? ¡Enfréntelas con amor! El Paso, EU: Editorial Mundo Hispano.

Beauvoir, Simone, De (2000). El segundo sexo. Madrid, España: Cátedra Universitaria de Valencia, Instituto de la Mujer.

BRONFENBRENNER, U. (1979). The ecology of human development: experiments by nature and desig. Cambridge, Inglaterra: Harvard University Press.

CAIRETA, M. (2008). “La mediación: ¿una herramienta o un fin?”, en Documentación Social, n. ${ }^{\circ} 148$, pp. 13-24.

Calvo González, Germán y Camacho Vejarano, Rafaela. (2014). La violencia de género: evolución, impacto y claves para su abordaje. Recuperado el 2 de noviembre de 2015, de http://www.um.es/global/: http://www.scielo.iscii.es.

Carvajal Rodríguez, Cirelda (2006). Prevención Integral y Promoción de Salud en la Escuela. La Habana, Cuba: Ministerio de Educación.

Castro Espín, Mariela (2006). El sexo como juez universal del ser humano. Memorias de la IV Conferencia Internacional de Derecho de Familia y Encuentro Internacional Mujer, Género y Derecho. Universidad de La Habana, Facultad de Derecho.

Chávez, Justo (2003). La Filosofía de la educación cubana desde finales del siglo XVIII hasta finales del XIX. La Habana, Cuba: Editorial Pueblo y Educación.

Constitución de la República de Cuba de 2002 (2010). La Habana: Editorial Política.

Coy, ERnesto y Martínez, María del Carmen (2006). Desviación Social: Una aproximación a la teoría y la intervención. La Habana, Cuba: Editorial Ciencias Médicas.

Del VAL, T. M.(2006). Mediación en materia penal la teoría y su aplicación. Casos de mediación penal juvenil. La prevención del delito a partir de la mediación, Leyes de mediación penal. Buenos Aires, Argentina: Adhoc. 
DíAZ, L. M. (2009). "La reparación: un rostro diferente en el derecho penal juvenil. Referencia al caso colombiano”, en Estudios, n. ${ }^{\circ} 72$, pp. 82-108.

DOUCET, LAN (1998). Buscando la paz del mundo: manual de recursos para la transformación del conflicto. Santafé de Bogotá: Ediciones Clara-Semilla.

Fernández Olazábal, Pedro; Riera Carmenates, Nidia y Salas Pérez, Luis (1998). "Caracterización psicosocial de la familia con violencia intradinámica", en Archivo Médico de Camagüey. Camagüey Cuba, pp. 1-12.

Fernández Plasencia, María de Jesús (2008). "Multimedia para contribuir a la prevención del uso indebido de drogas en alumnos y docentes de la Enseñanza Primaria”. Tesis en opción al título académico de Máster en Ciencias Pedagógicas. Matanzas, Cuba.

Flanders, Elen et al.(1994). Proyecto de Alternativas a la Violencia. Manual curso básico. Santafé de Bogotá: Centro Cristiano Justapaz.

González, Alicia y Castellanos, Beatriz (2003). Sexualidad y géneros. Alternativas para su educación ante los retos del siglo XXI. La Habana, Cuba: Editorial Científico Técnica.

GoRDILLO, L. F. (2007). La justicia restaurativa y la mediación penal, Madrid, España: Lustel.

GozAIni, O. A. (2009). La mediación: una nueva metodología para la resolución de controversias. Ponencia presentada al I Congreso Internacional de Derecho Procesal, La Habana, Cuba.

Hernández Pita, IyAmira (2014). Violencia de Género. Una mirada desde la sociología. La Habana, Cuba: Editorial Científico-Técnica.

INFANTE, L. y RIVERO, M. (2007). “La educación en la diversidad para una enseñanza desarrolladora". Documento presentado en el curso preevento Pedagogía, Palacio de las Convenciones. La Habana, Cuba.

Jorrín Perdomo, Odalis (2012). “Caracterización de la violencia de pareja contra la mujer en la zona de Canímar, Matanzas”. Tesis en opción a la especialidad de primer grado de Medicina General Integral. Matanzas, Cuba.

Kraybill, Ronald S. (2003). Destrezas para la Paz. Manual para Mediadores Comunitarios. California, USA: Jossey-Bass Inc., Wiley Company. 
LARRAURI, E. (2004). “Tendencias actuales de la justicia restauradora”, en Estudios de Derecho, Vol. 61, n. ${ }^{\circ} 138$, pp. 55-85.

Lederach, JuAn PABlo (1992). Enredos, pleitos y problemas. Ciudad de Guatemala: Ediciones Clara-Semilla, 1992.

Lederach, Juan Pablo y Cupp, Marcos (1997). ¿Conflicto y violencia? : ¡Busquemos alternativas creativas! Santafé de Bogotá: Ediciones Clara-Semilla.

López-Cepero Borrego, J.; Rodríguez Franco, L.; Rodríguez Díaz, F. y BrinGas Molleda, C. (2010). "Ya no quisiera ni ser yo: La Experiencia de la violencia doméstica", en Revista Interpsiquis, febrero-marzo de 2010. Recuperado el 25 de enero de 2012, de http://www.interpsiquis.com.

MÁrquez,A. E. (2007). "La justicia restaurativa versus la justicia retributiva en el contexto del sistema procesal de tendencia acusatoria”, en Prolegómenos-Derechos y valores, Vol. XX, n. ${ }^{\circ} 20, \mathrm{pp} .99-114$

Mazo Álvarez, Héctor Mauricio (2013). La mediación como Herramienta de la justicia restaurativa. Recuperado el 15 de noviembre de 2015, de http://www.scielo.cl

Mesa Villavicencio, Paulina (2006). "El trabajo de los Centros de Diagnóstico y Orientación”, en El trabajo de los Centros de Diagnóstico y Orientación. La Habana, Cuba: Editorial Pueblo y Educación, pp. 79-81.

Mesa Villavicencio, P.; Leyva, M.; LóPez, R.; Álvarez, C.; Ricardo, M. y NúÑ̃z, O. (2006). El trabajo de los Centros de Diagnóstico y Orientación. Concepciones básicas de actualidad. La Habana, Cuba: Editorial Pueblo y Educación.

MoOre, C. (1986). El proceso de mediación métodos prácticos para la resolución de conflictos. Buenos Aires, Argentina: Granica.

Moya, César y Toledo, César Ezequiel (2000) Caminos de Paz. Manejo de conflictos en cárceles. Quito, INREDH.

Nieto Almeida, LÁzaro Emilio (2005). "Modelo de superación profesional para el perfeccionamiento de las competencias profesionales en la actividad educativa con profesores de los ISP". Tesis en opción al grado científico de Doctor en Ciencias Pedagógicas. Santa Clara, Cuba, 2005.

OBARRIO, F. M. (2009). “Algunos aspectos institucionales de la mediación”, en Revista del Colegio de Abogados de la ciudad de Buenos Aires, Vol. 55, n. 1, pp. 23-37. 
Organización PANAMERICANA DE LA SALUd (2003). Informe mundial sobre la violencia y la salud. Washington, OPS.

Pick, Susan; Leenen, Iwin; Givaudan, Martha y Prado, Andrea (2010). Yo quiero, yo puedo... prevenir la violencia: programa breve de sensibilización sobre violencia en el noviazgo. Recuperado el 2 de noviembre de 2015, de http://www.scielo.org.

Póo, Ana María y Vizcarra, Beatriz (2015). Violencia de Pareja en Jóvenes Universitarios, 2008. Recuperado el 2 de noviembre de 2015, de http://www.scielo.cl, p.1. RIPÒL, A. (2001). Familias, trabajo social y mediación. Buenos Aires, Argentina: Paidós.

Rivero García, DANilo y Bertot Yero, María CARIDAD (2009). Ley número 62/87 o Código Penal de la República de Cuba (Anotado con las disposiciones del CGTSP). La Habana, Cuba: Ediciones ONBC.

Romero, F. (2002). “La mediación familiar. Un ejemplo de aplicación práctica: la comunicación a los hijos de la separación de los padres. El papel del mediador", en Revista del ministerio y asuntos sociales, $\mathrm{n} .^{\circ} 40$, pp. 31-54.

Salazar Villarroel, D. y Vinet Reichhardt, E. (2011). Mediación familiar y violencia de pareja. Recuperado el 15 de noviembre de 2015, de http://www.scielo.cl

Segovia, J. L. y Ríos, J. (2008). Diálogo, justicia restaurativa y mediación, en Documentación social, $\mathrm{n} .^{\circ}$ 148, pp. 77-97.

SuÁREZ, M (2003). Mediando en sistemas familiares. Buenos Aires, Argentina: Paidós.

Valdés Jiménez, Yohanka; Díaz Tenorio, Mareelén; Perera Pérez, Maricela; Chao Hernández, Ana María; Rodríguez Álvarez, Neury; Gazmuri Núñez, Patricia; Morgado García, Aylín y García Córdova, Aleida (2012). Violencia de género en las familias, La Habana, Cuba: Publicaciones Acuario.

VArgas PaVez, M. (2008). Mediación obligatoria. Algunas razones para justificar su incorporación. Recuperado el 15 de noviembre de 2015, de http://www.scielo.cl

WiLde, Z. (2000). “Mediación y conciliación”, en Revista del Colegio de Abogados de la ciudad de Buenos Aires, Vol. 55, n. ${ }^{\circ} 1$, pp. 7-14. 